\title{
Intramonth oscillations of Atlantic ITCZ observed in SMAP satellite salinity
}

\author{
Grodsky Semyon A. ${ }^{1,{ }^{*}}$, Reul Nicolas ${ }^{2}$, Vandemark Douglas ${ }^{3}$, Bentamy Abderrahim ${ }^{2}$
}

${ }^{1}$ Department of Atmospheric and Oceanic Science, University of Maryland, College Park, MD, USA

2 CNRS, IRD, Laboratoire d'Oceanographie Physique et Spatiale (LOPS), IUEM, IFREMER, Univ.

Brest, Brest, France

${ }^{3}$ Institute for the Study of Earth, Oceans, and Space, University of New Hampshire, Durham, NH, USA

* Corresponding author : Semyon A. Grodsky, email address : senya@atmos.umd.edu

\begin{abstract}
:
The time variability of wind and rainfall in the Atlantic Intertropical Convergence Zone (ITCZ) has a wide oscillation spectrum that includes strong intra-month periodicities. These latter short-period oscillations span from individual convection lifecycle events of a few hours to longer pentad and multi-week convective cluster periods. This study reports on measured ITCZ rain variability at periods of a few weeks and its imprint on sea surface salinity (SSS) observed using satellite remote sensing. Despite small amplitude of variations of only 0.1-0.2 psu, these changes are shown to be detectable in radiometer SSS estimates collected by the Soil Moisture Active Passive (SMAP) satellite. They are shown to develop in the midAtlantic ITCZ latitude band and to follow its seasonal meridional progression. These rain-correlated sea surface signatures appear quasi-synchronously across a wide range of longitude. Both the ITCZ-related seasonal migration and high zonal propagation speeds distinguish these intra-month SSS oscillations from that of tropical instability waves (TIW), with TIWs having periods greater than 1 month and slower westward propagation. While detection of tropical Atlantic TIW salinity signatures using satellite data has received significant attention, it appears that atmospheric freshwater forcing impacts on the upper ocean at these shorter periods represents an additional process resolvable from space using SMAP. Correlation analyses of precipitation and winds indicate that low latitude convection clusters are accompanied by an upward Ekman pumping anomaly, which uplifts saltier water to surface layers diluted by enhanced precipitation. These vertical processes modify the salt balance and change the phase relationship between the oceanic SSS response and the atmospheric freshwater forcing.
\end{abstract}


48 One of the major sources of intraseasonal variations of near surface salinity in the tropical oceans

49 is associated with oceanic tropical instability waves (TIW). Mixed layer current perturbations

50 produced by TIWs induce cusp-shaped features in the sea surface temperature (SST) (e.g.,

51 Weisberg and Weingartner 1988), sea surface salinity (SSS), (e.g., Grodsky et al. 2005), sea

52 surface height (SSH) (e.g., Polito et al. 2001), and Chlorophyll-a (Chl-a) (e.g., McClain et al.

53 2002). In the Pacific, wave-induced meridional excursions of salty and cold equatorial water

54 periodically produce negatively correlated SST and SSS signatures that propagate westward at

55 characteristic TIW speed of less than about $1 \mathrm{~m} \mathrm{~s}^{-1}$, periods of 20-40 days, and wavelengths of 
56 1000- $2000 \mathrm{~km}$ e.g., (Chelton et al. 2001). In the Atlantic, TIW signatures are generally similar

57 to Pacific TIWs but have somewhat shorter wavelengths $(<1000 \mathrm{~km})$, e.g., (Lee et al. 2014).

58 TIW-induced sea surface salinity structures have been detected in satellite salinity data obtained

59 from orbiting L-band radiometers (Lee et al. 2012); (Yin et al. 2014). Differing from SST and

60 SSH, TIW SSS signatures in the Eastern Pacific were found strongest at the equator. The satellite

61 SSS imagery revealed that the dominant westward propagation speed of TIW at the equator is

62 twice as fast as the TIW phase speed widely reported in the literature, which is mostly based on

63 observations of SST and SSH away from the equator. These intraseasonal salinity perturbations

64 are not simply TIW manifestations. They can also have an important effect on the magnitude of

65 baroclinic energy transfer cascades in the tropical oceans due to significant meridional gradient

66 of salinity (that between the saline equator and relatively fresh ocean of the Intertropical

67 Convergence Zone, ITCZ) and the corresponding large magnitude of TIW-salinity perturbations,

68 which contribution to water density perturbations is significant (Grodsky et al. 2005; Lee et al.

69 2014).

70 Atmospheric boundary layer interactions with TIW-induced SST gradients can result in 71 remarkably coupled spatio-temporal variations of winds, wind curl, and wind divergence

72 (Chelton et al. 2001). The coupling between SST gradients and winds confirms earlier

73 observations indicating that surface winds respond to SST-induced changes in marine

74 atmospheric boundary layer thermal stability (e.g., Beal et al. 1997). Moreover, TIW-modulation

75 of the wind divergence may also induce organization in atmospheric convection and rainfall,

76 with additional impacts on the original TIW-related surface salinity perturbations. While such

77 equatorial TIW salinity signatures and eddy salinity signatures (Melnichenko et al. 2017);

78 (Hasson et al. 2019) have received significant attention, surprisingly, there has been less

79 examination of tropical ocean salinity change due to atmospheric freshwater forcing at

80 frequencies higher than seasonal and apart from TIW influences.

81 TIW-induced wind perturbations represent one example of local air-sea interactions that

82 contribute to the cluster organization of tropical convection. On much larger scales, the most

83 notorious organization is associated with the Madden-Julian Oscillation (MJO), a 30- to 90-day

84 variability in the tropical atmosphere that propagates eastward at approximately 4 to $8 \mathrm{~m} \mathrm{~s}^{-1}$.

85 MJO oscillations exhibit maximum amplitude over the Indian and western Pacific Oceans and 
86 their impacts on the upper ocean have been detected in satellite remote sensing salinity (e.g.,

87 Shinoda et al. 2013; Guan et al. 2014). Although (Foltz and McPhaden 2004) reported wind 88 oscillations in a similar frequency band (30-70day) over the Atlantic, the MJO impacts east of

89 the dateline, including the Atlantic sector, are less prominent. In the tropical Atlantic, the 90 intraseasonal 30-80 day eastward-propagating convection and rainfall clusters (similar to the

91 MJO) have been observed by (Gu 2009). These rainfall anomalies appear first in the

92 northwestern tropical Atlantic right off the coast of South America and gradually extend

93 eastward to cover the entire basin. In the Atlantic ITCZ, a shorter scale, 15-20 day variability is

94 also present, which (Tomaziello, Carvalho, and Gandu 2016) associate with mid-latitude Rossby

95 wave trains in the cold Hemisphere. The above two significant spectral peaks reflect in rainfall

96 and winds not only over the Atlantic but also in tropical West Africa as well e.g. (Maloney and

97 Shaman 2008).

98 The global view provided by satellite imagery has helped to illustrate that tropical convection 99 can be organized at a wide range of spatial and temporal scales, from mesoscale convective 100 systems to planetary-scale Madden-Julian Oscillations (Kiladis et al. 2009), scales that are 101 virtually impossible to observe without such imagery. In monsoon regions, precipitation can 102 appear to be organized on monthly and shorter periods (Krishnamurti and Bhalme 1976). In the 103 Atlantic ITCZ, spatially coherent bi-weekly oscillations in winds and rainfall associated with the 104 west African monsoon have been observed by Grodsky and Carton, (2001). At shorter periods, 105 the tropical convection is normally clustered by waves that move eastward, or westward, either 106 along the equator or within the ITCZ (Kiladis et al. 2009). Such convectively-coupled equatorial 107 waves introduce a band intra-month organization in the tropical convection and rainfall within 108 bands that seasonally migrate with the ITCZ.

109 This paper uses multi-year satellite datasets over the tropical Atlantic to identify likely

110 precipitation events associated with convective clusters that are organized in a few week-long 111 oscillations and, in turn, their imprint on SSS as measured using data from the Soil Moisture 112 Active Passive (SMAP) satellite mission. While L-band radiometer imaging has shown some 113 capability to detect the impact of strong individual rain events on both horizontal and vertical 114 gradients of near surface ocean salinity (Boutin, Chao, et al. 2016; Boutin, Martin, et al. 2016) 115 and even infer rainfall from SSS data (Supply et al. 2018), continuous satellite monitoring of 
116 such events is not feasible due to the polar-orbit satellite sampling issues (full coverage requires

117 roughly 3 days with a repeat cycle of 8 days), which allows systematic detection only of integral

118 impact of cumulated rainfall (Boutin et al. 2013). Here, we focus instead on the satellite

119 detection of the possible time-integrated ocean impacts of organized convection on SSS

120 considering the longer time scale of convective/rainfall clusters with periods of about 3 weeks.

121 Satellite salinity missions operate in the L-band $(1.4 \mathrm{GHz})$ where water emissivity depends on

122 salinity. The background Earth thermal radiation in this band is almost 7 orders of magnitude

123 weaker than in the infrared band widely used for SST. Such weak L-band radiation makes SSS

124 retrieval challenging. Nevertheless, satellite SSS is reasonably close (to within $0.2 \mathrm{psu}$ ) to quasi-

125 synchronous in-situ data in the tropics (e.g., Lee, 2016). But such SSS accuracy is about 3\% of

126 its global ocean range $(32-38 \mathrm{psu})$ in comparison to $0.1^{\circ} \mathrm{C}$ accurate $\mathrm{SST}$, which accuracy is

127 about $0.3 \%$ of its range $\left(0-30^{\circ} \mathrm{C}\right)$. Although the time mean dilution by ITCZ rainfall reaches

$128 \sim 1$ psu and is routinely detectable, the detection of smaller magnitude signals is not apriori

129 achievable. This paper shows that besides well-known intraseasonal ocean SSS variations

130 associated with TIW, there exist atmospheric-induced component of intraseasonal SSS

131 associated with convection clustering. Regardless of its small amplitude of $0.1-0.2 \mathrm{psu}$, it is

132 detectable by satellite SSS remote sensing.

133 Wind-induced intraseasonal ocean oscillations are known to exist in the equatorial wave guide

134 (e.g., Grodsky, Carton, and McClain 2008), but are also present at higher latitudes. Part of the

135 impetus for this study comes from (Krishnamurti and Bhalme 1976) and (Grodsky and Carton

136 2001) who identified the presence of approximately bi-weekly oscillations in both surface wind

137 and rainfall in Indian and west African monsoon systems. Such oscillations are tied with the

138 corresponding monsoon and are seasonally present along with the monsoon. But, as

139 demonstrated further, similar intramonth transients are present in the tropical atmosphere

140 (precipitation, winds) and ocean response (SSS) all year long and occupy vast areas of the

141 tropical open-ocean beyond coastal regions affected by monsoons.

142 To describe and analyze these intramonth oscillations, the presentation is organized in the

143 following way. First, we demonstrate the presence of accorded intramonth variations in

144 precipitation and satellite-observed SSS in the central north tropical Atlantic, which meridional

145 location follows the ITCZ. Next, we perform correlation analyses between intramonth variations 
146 of SSS, precipitation, and surface wind divergence that show an almost out-of-phase relationship

147 between SSS and precipitation variations. This out-of-phase relationship suggests that other

148 factors besides the pure surface forcing are involved, among which the ocean Ekman pumping

149 and the fast relaxation of rain-induced salinity anomalies are found contributing to the phase

150 characteristics of SSS response. Finally, we discuss precipitation and wind satellite data to

151 illustrate how atmospheric convective clusters originate and propagate along the Atlantic ITCZ.

\section{2. Data and methods}

153 Satellite salinity: This study relies on satellite SSS from the Soil Moisture Active Passive

154 (SMAP) mission. Global Level 3 SMAP SSS is available daily as an 8-day running mean on a

$1550.25^{\circ}$ grid (Version 3) produced by the Remote Sensing Systems,

156 www.remss.com/missions/smap, (Meissner, Wentz, and Vine 2018). The surface footprint of

157 each measurement is $39 \times 47 \mathrm{~km}$ so the effective resolution is close to $40 \mathrm{~km}$. On monthly and

$158 \sim 100 \mathrm{~km}$ scales, satellite SSS values match with in-situ measurements in the warm tropics to

159 within $\sim 0.2 \mathrm{psu}$, (Lee 2016). Due to several limitations (e.g., remaining residual error due to

160 extra-terrestrial radiation, ionospheric effects, land-sea transitions, and sea surface roughness

161 impacts on the radiometer brightness temperatures), satellite SSS often exhibit systematic

162 seasonally-dependent biases versus ground truth (Meissner et al. 2016). As shown by several

163 studies (e.g., Boutin, Martin, et al. 2016), the SSS anomaly (SSSA) determined from the

164 background longer-term satellite SSS data, (i.e., the difference computed relative to a slow

165 varying SSS signal, such as a monthly satellite-based SSS climatology) is significantly less

166 affected by these seasonal biases. The filtering procedure effectively removes such retrieval

167 artifacts along with any actual slow varying SSS component. For the entire SMAP observation

168 period (April 2015 - onward), the intra-month SSS variation at each grid point was estimated as

169 the difference of observed SSS from its monthly moving mean.

170 Other satellite data: Satellite SST data come from the Canadian Meteorological Centre. Here we

171 use the level 4 SST produced by combining infrared, microwave, and in-situ daily analyses

172 resampled at $0.25^{\circ}$ spatial resolution. These SST data are used for the SMAP SSS processing

173 and included in SMAP data files. The using of microwave-derived SST is important in this

174 cloudy ITCZ region. To characterize the surface wind, we use the gridded daily 10m neutral

175 winds from the ASCAT scatterometer onboard the European Meteorological Satellite 
176 Organization MetOp which are described in (Bentamy and Fillon 2012) and available at

177 (ftp.ifremer.fr/ifremer/cersat/products/gridded/MWF/L3/ASCAT).

178 The precipitation data set is the Tropical Rainfall Measuring Mission (TRMM) Level 33B42v7

179 (Huffman et al. 2007). This is constructed by merging active and passive TRMM microwave

180 along with microwave-calibrated infrared measurements

181 (http://dx.doi.org/10.5067/TRMM/TMPA/3H/7). The TRMM orbit is specifically designed to

182 achieve rapid repeat sampling at low latitudes. The TRMM data set has $0.25^{\circ} \times 0.25^{\circ}$ spatial

183 resolution and is available from $1998-2018$.

184 3. Results

1853.1 General characteristics of intramonth salinity variations

186 In order to explore such transient rainfall-induced SSS features using SMAP SSSA data, we

187 choose to focus on an area where local precipitation is the primary term in the surface salinity

188 budget. The large scale SSS distribution in the tropical Atlantic reflects the meridional pattern of

189 the net freshwater flux with higher SSS in the evaporative subtropics and fresher SSS in the rainy

190 tropical belt (Fig. 1a). Within the fresh tropical belt, the meridional position of SSS minimum

191 roughly coincides with the ITCZ and there is also some significant west-to-east asymmetry.

192 While the time mean ITCZ rainfall and corresponding wind convergence are apparently lower in

193 the west (Figs. 1b, c), the SSS is fresher there in response to Amazon-Orinoco freshwater river

194 discharge. The band of fresh SSS associated with these river discharge and advection extends

195 from the shelf out into the central tropical Atlantic, reflecting seasonal eastward transport in the

196 North Equatorial Counter Current (NECC). However, in the central tropical Atlantic (around

$19730^{\circ} \mathrm{W}$ ), there exists a local SSS maximum in otherwise fresh zonal SSS band that separates

198 relatively fresher water to the east and to the west of it. This implies different freshwater forcing

199 mechanisms for the eastern and western edges of the basin. While the western fresh pole is

200 primarily influenced by river discharge (e.g., Foltz et al. 2004; Coles et al. 2013), the eastern

201 pole is more strongly driven by the local net freshwater forcing. In the east, this latter assumption

202 is corroborated by mostly eastward local zonal currents associated with the NECC, which deflect

203 the entrance of Gulf of Guinea fresh waters. Moreover, twin model experiments with the same

204 atmospheric forcing but differing river discharges show that the entire eastern pole of fresh SSS

205 is present even in simulations completely lacking any river discharge, including the Congo River 
206 (Dr. Ricardo Matano of OSU, personal communication, see also (Vizy and Cook 2010) for

207 changes in atmospheric patterns). In the meridional plane, there exists also a northward

208 displacement of the low salinity belt relative to the latitudinal position of ITCZ rainfall. This

209 displacement is attributed to the time mean northwestward Ekman transport produced by the

210 northeasterly trade winds (e.g., Grodsky, Carton, and Bryan 2014; Yu 2015).

211 Spatial structure of the time mean magnitude of intramonth SSS variability amplifies near the

212 western and eastern boundaries due to river discharge impacts (Fig. 1d). More certainly, it is

213 organized into two zonally elongated bands. The southern band extends along and just north of

214 the equator and reflects the presence of intramonth, approximately 17-day TIWs (Grodsky et al.

215 2005; Lyman, Johnson, and Kessler 2007; Lee et al. 2012). The second band of increased SSS

216 variability is located to the north of the equatorial band and is connected to the area of strong

217 SSS variability in the western boundary (Fig. 1d), notably via the retroflection of the North

218 Brazil Current. But in the central Atlantic, the SSS variability in the northern band is dominantly

219 driven by the corresponding atmospheric forcing (Figs. 1e, f). This was discussed in previous

220 studies (e.g., Yu 2011; Sena Martins, Serra, and Stammer 2015; Tzortzi et al. 2016). Intramonth

221 SSS variability in the central Atlantic box and its causes will be further explored here by

222 correlation analyses of oceanic and atmospheric fields.

223 The atmospheric-driven nature of intramonth SSS oscillations can be inferred via their

224 meridional behavior seen in Fig. 2a. Averaged over the zonal extent of the central Atlantic box

$225\left(30^{\circ} \mathrm{W}-15^{\circ} \mathrm{W}\right.$, see Fig. 1a for the box location), the area of enhanced intramonth SSS variability

226 in Fig. 2a closely follows the meridional ITCZ and wind divergence anomaly (divUA)

227 displacements (compare Figs. 2a, 2b, and 2d). These intramonth oscillations occur quasi-

228 synchronously with latitude (to within the temporal resolution of Fig. 2a) and coherently with

229 rainfall and surface wind divergence oscillations (Fig. 2b, 2d). Using spatial averaging over the

230 central north tropical Atlantic box (Fig. 1a), which is $15^{\circ}$-wide in longitude, allows filtering out

231 the majority of Atlantic TIW signatures.

232 In contrast with SSSA, Fig 2c suggests that the SST change does not follow intramonth ITCZ

233 variations. The latter variations do display an equatorial band of SST variability associated with

234 high frequency TIWs. Some of these TIW-induced variations are also detectable in intramonth

235 SSS, especially in summer (Fig. 2a). SST oscillations are also amplified in the northeasterly 
236 trade wind regime north of the ITCZ. The latter observation may suggest that organized ITCZ

237 clustered rainfall leads to wind perturbations that extend well away from these rainfall clusters,

238 which, in turn, modify SST through their impact on latent heat fluxes. These wide spread wind

239 anomalies will be demonstrated in composite patterns analyzed below.

240 A longitude-time view of intramonth SSS (Fig. 3a) confirms that salinity variability is observed

241 quasi-instantaneously over $30^{\circ} \mathrm{W}-15^{\circ} \mathrm{W}$ longitude band and is associated with fast-moving

242 variations in atmospheric forcing. Along with the atmospherically-induced signal, a westward

243 propagating TIW-induced signal is also present and distinguishable in all variables shown in Fig.

2443 , in particular, during the equatorial low rainfall period of the summer of 2015. This remaining

245 TIW-related signal is still distinguishable after $15^{\circ}$ zonal averaging even though the

246 characteristic wavelength of Atlantic TIW ( $<1000$ km, e.g., Grodsky et al. 2005) is normally

247 smaller than that for Pacific TIW that is evident by sample SST fields in Fig. 4. Spatial averaging

248 over the central north tropical Atlantic box allows for significant (but not complete) filtering out

249 of TIW-related signals and thus emphasizing of longer scale variability associated with

250 atmospheric transients.

\subsection{Correlation between intramonth SSS and precipitation}

253 Temporal SSS variations in the central tropical Atlantic box show that they are organized in at 254 least two frequency bands (Fig. 5). Low frequency (>30 days) box-averaged SSS (see Fig. 1a for 255 the box location) essentially depicts the seasonal cycle with distinct semi-annual variations (Fig.

256 5a) on top of the significant interannual variability. Fig 5b suggests these semi-annual SSS

257 variations can be largely explained by the semi-annual seasonal cycle of surface freshwater

258 forcing that peaks twice a year with north-south ITCZ migration across the box (e.g., Foltz et al.

259 2004). Some remaining disconnect between magnitudes of the low frequency SSS and

260 precipitation variations, especially noticeable during a fresh period in autumn 2017, reflects the

261 presence of notorious interannual variability and suggests that other factors including the

262 background vertical stratification (mixed layer depth) and the ocean currents may also impact

263 SSS variations. 
264 Visual inspection of intramonth variations indicates an apparent negative correlation between

265 precipitation enhancements and SSS decreases that are clearly seen in 8-day averaged raw data in

266 Figs. 5a, 5b. Note that precipitation in Fig. 5b is also 8-day averaged to match the 8-day SSS

267 averaging of satellite SMAP gridded salinity. The period of these precipitation and SSS

268 oscillations is approximately 3 weeks (spectra are discussed later). The negative correlation

269 between SSS and precipitation variations suggests the dominant role that surface freshwater flux

270 plays in driving central tropical Atlantic SSS at a wide range of seasonal and intraseasonal

271 periods. For intramonth periods, this negative correlation is further detailed in Fig. 5c, showing

272 that the majority of positive/negative SSS deviations coincide with negative/positive

273 precipitation change. Such a phase relationship is not fully expected because the maximum

274 dilution is expected by the end of the rainfall event, which implies a $\pi / 4$ phase delay between

275 SSS freshening and rainfall.

276 As expected from Fig. 2a, the area of negatively correlated intramonth SSS and precipitation

277 migrates meridionally following seasonal displacements of the ITCZ (Fig. 6). It shifts northward

278 in the boreal summer and autumn and then back towards the equator in the winter and spring.

279 The magnitude of the correlation is statistically significant (Fig. 6) but normally doesn't exceed

280 0.5. This weak level may be attributed to the SSS noise because the relatively weak magnitude of

281 intramonth SSS (<0.2 psu) is near the edge of satellite retrieval accuracy (e.g., Lee 2016).

282 Another possible explanation may be the satellite's temporal SSS data coverage, which employs

283 8-day averaging for gridded fields. Such averaging of independent in-swath satellite observations

284 may alias on longer periods and thus limit the magnitude of intramonth correlations.

285 Lagged correlation between timeseries of parameters area-averaged over the central tropical

286 Atlantic box indicates that zero-lag correlation shown in Fig. 6 yields nearly the highest

287 magnitude (Fig. 7b). Only a slight delay (a few days) between peaks of near-surface wind

288 divergence and precipitation (Fig. 7a) is observed, and this is similar for precipitation and SSS

289 (Fig. 7b).

$290 \quad 3.3$ Ekman pumping impact on intramonth SSS

291 The characteristic amplitude of intramonth SSS is about $\delta S=0.1 \mathrm{psu}$ (Fig. 5c). In terms of the

292 mixed layer salt budget, the magnitude of $\delta S$ is roughly consistent with the magnitude of 
293 organized rainfall oscillations in the ITCZ, $\delta P=5 \mathrm{~mm} \mathrm{day}^{-1}$ (Figs. 2b, 5c). This level would

294 give an SSS variation of, $\delta S=\frac{S \delta P}{D} \delta t=0.05 \mathrm{psu}$, if acted on for $\delta t=14$ days and with a

295 typical local ocean mixed layer depth of $D=50 \mathrm{~m}$. Although it is only a half of the observed

$296 \delta S=0.1 \mathrm{psu}$, it is known that intense ITCZ rainfall produces shallow barrier layers, see e.g.,

297 Fig.2 in (Liu, Grodsky, and Carton 2009). Hence, surface freshwater flux anomalies may act on a

298 layer shallower than $D=50 \mathrm{~m}$ and thus induce stronger SSS oscillations. Although the

299 magnitude of $\delta S$ is roughly consistent with the surface forcing scenario, the observed anti-

300 correlation between SSS and precipitation variations (rather than rainfall leading SSSA

301 integrated effects) suggests that other factors besides the pure surface forcing are involved (Fig.

$3025 \mathrm{c})$.

303 While the approximately out-of-phase relationship (negative correlation) between $\operatorname{div} U$ and

304 precipitation is fully expected for tropical convection events, the almost out-of-phase relationship

305 between precipitation and ocean SSS response is surprising. If the salinity rate of change was

306 solely balanced by the precipitation $(\partial S / \partial t \sim \delta P)$, this would imply a so-called quadrature phase

307 relationship between precipitation and salinity, (rainfall variation, $\delta P$, leads SSSA integrated

308 effect, $\delta S$, by a quarter of period). The observed deviation from this phase relationship suggests

309 that other factors must contribute to intramonth salinity change. In fact, it is assumed that

310 organized precipitation (convection) clusters are accompanied by anomalous wind curl, which

311 alters the Ekman pumping, $W_{\mathrm{EK}}=-1 / \rho_{\mathrm{w}} \operatorname{curl}\left(\tau_{\mathrm{x}} / f, \tau_{\mathrm{y}} / f\right)$. Here, $\left(\tau_{\mathrm{x}}, \tau_{\mathrm{y}}\right)$ are the zonal and

312 meridional surface wind stress components, $\rho_{\mathrm{w}}$ is the water density, and $f$ is the Coriolis

313 parameter. Lagged correlation in Fig. 7c illustrates the presence of in-phase variations between

314 intramonth precipitation and $W_{\mathrm{EK}}$ (upward $W_{\mathrm{EK}}$ is positive). Hence, for low latitude convective

315 clusters, the upward Ekman pumping brings saltier water to the surface that mixes with waters

316 diluted by enhanced precipitation.

317 Correlation between Ekman pumping and convective clusters may be caused by organized

318 cyclonic winds associated with the clusters, or by alternative factors. Fig. 8 explores likely

319 alternatives showing several ocean and atmosphere parameters averaged over typical wet and dry

320 events in the central Atlantic. These events are defined as periods when the magnitude of box-

321 averaged intramonth precipitation anomaly exceeds its standard deviation ( $2.5 \mathrm{~mm}$ day $\left.{ }^{-1}\right)$. Note,

322 that this threshold is lower than rainfall standard deviation in Fig. 1e, where grid point rather 
323 than box averaged values are shown. Due to the rainfall dilution, it is expected that wet and dry 324 composites correspond to fresh and salty anomalies, respectively (Figs. 8a, b). The characteristic 325 magnitude of intramonth SSS anomalies is about 0.1 psu in line with Fig. 5c. Wet and dry events 326 are accompanied by convergent and divergent wind patterns, respectively, with the sign agreeing 327 with corresponding changes in atmospheric convection and related precipitation (Figs. 8c, d).

328 Wind velocity and curl anomalies associated with changes in intramonth precipitation are 329 roughly symmetrical versus the center latitude of the box, but the pattern of $W_{\mathrm{EK}}$ is not (Figs. 8e,

330 f). This asymmetry is related to the latitudinal dependence of the Coriolis parameter, which

331 amplifies the magnitude of $W_{\mathrm{EK}}$ approaching the equator. This latitudinal asymmetry is

332 characteristic of Ekman pumping at low latitudes. As a result, during wet/dry events, the box

333 averaged $W_{\mathrm{EK}}$ is upward/downward, respectively. This vertical exchange then partially balances

334 anomalous net freshwater forcing, impacting the salt budget and altering the phase relationship

335 between the oceanic SSS response and rainfall.

\section{4. Discussions}

337 To provide further insight into the correlations discussed above, an expanded example of short338 term wind and precipitation shifts at intramonth event scale is next examined for the November339 December 2017 timeframe singled out in Fig. 5c. Fig. 9 provides a 2-day average spatio340 temporal view for one positive/dry (Fig. 9 b-h) and a following negative/wet (Fig.9 j-p) SSSA 341 period. The results indicate a high correspondence between event-mean precipitation (Figs. 9a, 342 9i) and SSS (see Fig. 5c). There exists an apparent difference in mean precipitation values 343 temporally averaged over a salty event (27 November - 10 December of 2017) and a fresh event

344 (10 - 23 December of 2017). But, it should be noted that zonally continuous band of ITCZ 345 rainfall is represented only in time averages while 2-day snapshots are dominated by mesoscale 346 convective systems (Fig. 9). These systems are thus seen in both precipitation and wind patterns 347 but are unresolved in 8-day SSS averages. During the salty event (Fig. 9, b-h), the mid-Atlantic 348 ITCZ was relatively quiet, especially during the first week (27 November -2 December). In the 349 next week (3-10 December), the ITCZ intensified starting with a cluster of enhanced rainfall 350 over the western tropical Atlantic area adjacent to South America (3-4 December). Interestingly, 351 this area of enhanced rainfall is associated with atmospheric convection over the ocean and 352 doesn't extend over the land. Next, this enhanced rainfall cluster propagated eastward along the 
353 time mean ITCZ, at a speed of 6 to $7 \mathrm{~m} \mathrm{~s}^{-1}$, finally reaching the Gulf of Guinea in about one 354 week.

355 The above episode of eastward propagation of convection during 3-10 December is the only dry356 period clear episode in Fig. 9. During the fresh event (10-23 December, Fig. 9, j-p), there is no 357 apparent eastward propagation of convection clusters. The main differences between

358 precipitation fields for wet and dry events is in the generally higher magnitude of rainfall for wet 359 events and the larger number of days of depressed rainfall for dry events (more quiet rainfall 360 days during dry periods).

361 Fig. 10 recalls this small sub-segment of the region of interest box-averaged intramonth SSS, 362 wind and rainfall data. Comparison of Fig. 10 and with Fig. 9 variations in daily precipitation 363 suggests that much of 8-day averaged precipitation/SSSA variation (Fig. 5c) is, in fact, an 364 integration of high frequency (1-4 day) mesoscale convective events. As mentioned before, 365 immediate surface ocean impacts of such precipitation spikes are unresolved in 8-day SSS 366 averages, but the integrated oceanic effects in this mid-Atlantic region are apparent.

367 As noted before, many factors, including wind stirring, Ekman pumping, and others, contribute 368 to fresh rain lenses decay. For each individual rainfall event, the SSS keeps freshening until the 369 cessation of rainfall, which introduces the phase delay with a characteristic time-scale 370 corresponding to individual rain event duration. Because SMAP SSS resoles only longer time 371 scales ( $>8$ days), it can detect the dilution effect of convective clusters only. Each such cluster 372 includes multiple individual rain events. In terms of cumulative freshwater deposit, these clusters 373 are equivalent to the combined effect of individual rainfall events. But for fast decaying 374 anomalies, the physical lag between SSS response and cumulative rainfall is not defined by the 375 time scale of convective clusters. It remains the same as that for individual rainfall events and is 376 defined by the short time-scale of individual rain events. This suggests that the integrated effect 377 of intermittent rainfall leads to different phase delays between rainfall and salinity response 378 depending on the characteristic decay time of fresh salinity anomalies. As schematically 379 illustrated in Fig. 11, a phase delay comparable with rainfall cluster time scales would 380 happen only if the signature of the precipitation (associated low SSS anomaly) remains for a 381 significant time at the ocean surface (slow decay case), and thus slowly accumulates 382 precipitation from the entire rainfall cluster. In contrast, if fresh anomalies decay considerably 
383 between individual rainfall events, the corresponding phase delay is smaller and defined by the

384 characteristic duration of individual rainfall events (fast decay case). The observed negative correlation between precipitation and SSS anomalies (Fig. 7b) suggests the second, fast decay case. This is corroborated by the observed near surface salinity anomaly decay time of less than

3871 day (Drushka et al. 2016).

In late fall through spring, the ITCZ shifts southward towards the equator, and a wide spectrum of atmospheric oscillations is observed over the central Atlantic box (Fig. 12a). Like in Fig. 10, the spectral analysis in Fig. 12 depicts few-day oscillations, approximately 3-week oscillations, and also longer (about 50- to 60-day) oscillations. The latter band of oscillations was described

392 by e.g., ( $\mathrm{Gu} 2009)$, but it was removed from our main analysis in order to focus on intramonth

393 frequencies. Both 3-week and 50-day oscillations are reflected in SSS and manifest in the 394 corresponding peaks of the SSS spectrum. When the ITCZ shifts northward, the spectrum of 395 precipitation becomes smoother while 3-week and $\sim 50$-day peaks hold (Fig. 12b). Despite even 396 stronger precipitation oscillations in summer months, they are not apparently reflected in the box-averaged SSS (Fig. 12b). During these months, the band of SSS oscillations shifts northward

398 following rainfall and weak winds in the ITCZ (Fig. 2a). During this period, the southeasterly 399 trade winds amplify over the fixed central north tropical Atlantic box area. Hence, the decreased 400 level of SSS oscillations during the period shown in Fig. 12b simply reflects that these amplified 401 winds stir rainfall fresh water vertically and thus decrease the magnitude of SSS response.

\section{5. Summary}

403 In summary, it is known that wind and rainfall in the Atlantic ITCZ experience a wide spectrum 404 of oscillations, including intra-month periodicities. However, the impact of such episodic rainfall 405 on the surface ocean freshwater in the tropics at similarly small time and space scales is largely 406 unknown. Some of these periodicities are related to the presence of approximately bi-weekly 407 oscillations of wind and rainfall in the West African monsoon (Grodsky and Carton 2001). But, 408 such monsoonal oscillations are tied with the corresponding monsoon and are seasonally present 409 along with the monsoon. Here it is demonstrated that accorded intramonth transients are present 410 in the tropical atmosphere and near-surface ocean salinity all year long, occupy vast areas of 411 internal ocean affected by ITCZ rainfall, and extend beyond coastal regions affected by 412 monsoons. Although such rain-induced SSS oscillations are expected to occur across the entire 
413 tropical Atlantic, their examination is limited to the central north tropical Atlantic box where the

414 surface net freshwater forcing is the leading driver of SSS and where river discharge effects are

415 less important.

416 This study reports on the presence of approximately 3 week ocean-atmosphere oscillations which

417 result from organized groups of mesoscale tropical convection clusters and their apparent

418 imprints on satellite-derived sea surface salinity (SSS). These SSS oscillations have a relatively

419 small amplitude of up to 0.2 psu but are clearly are detectable in Soil Moisture Active Passive

420 (SMAP) SSS retrievals at resolutions as short as 8-days and spatial scales of 50-100 km. These

421 SSS oscillations are produced by the corresponding precipitation oscillations, which are most

422 intense in the ITCZ. As a result, the SSS oscillations develop in the ITCZ latitude band and

423 follow its seasonal meridional displacements. They also develop quasi-synchronously in a wide

424 range of longitudes. These seasonal displacements and high zonal speeds distinguish rainfall-

425 forced intramonth salinity oscillations from signatures of tropical instability waves (TIW) which

426 normally have periods exceeding 1 month and distinct slow westward propagation.

427 Lagged correlation of intramonth SSS and precipitation timeseries box-averaged over the central

428 Atlantic box $\left(30^{\circ} \mathrm{W}-15^{\circ} \mathrm{W}, 2^{\circ} \mathrm{N}-6^{\circ} \mathrm{N}\right)$ indicates only a slight delay $(<2-3$ days $)$ between

429 peaks of high precipitation and SSS decrease. The almost out-of-phase relationship between

$430 \sim 3$-week precipitation events and ocean SSS response is unexpected. If the salinity rate of

431 change was balanced by the precipitation only, it would imply a quadrature ( $\pi / 4)$ phase delay

432 between precipitation and salinity variations, with negative salinity anomaly peaking at the end

433 of a rainy period. The deviation from this phase relationship implies that other factors, including

434 salt anomaly dissipation, also contribute at intramonth periods. Besides commonly considered

435 vertical turbulent dissipation, we also show that low latitude organized precipitation (convection)

436 clusters are accompanied by an upward Ekman pumping anomaly that entrains saltier water to

437 surface layers diluted by enhanced precipitation. All these vertical processes contribute to fast

438 ( 1 day) rainfall lenses decay and modify the salt balance and change the phase relationship

439 between the oceanic SSS response and the atmospheric freshwater forcing. This leads to almost

440 out-of-phase relationship suggesting that maximum dilution coincides with rainfall peaks even

441 on time scales of few-week rainfall clusters. 
442

443

444

445

446

447

448

449

450

451

452

453

454

455

456

457

458

459

460

461

462

463

464

465

466

467

468

469

470

471

472

473

474

475

476

477

478

479

480

481

Acknowledgements This research was supported by the NASA Ocean Salinity Science Team (OSST) grants NNX17AK08G and NNX17AK02G. All data providers are acknowledged for making their products freely available. SMAP salinity data are produced by Remote Sensing Systems and sponsored by the NASA/OSST.

\section{References}

Beal, R.C., V.N. Kudryavtsev, D.R. Thompson, S.A. Grodsky, D.G. Tilley, V.A. Dulov, and H.C. Graber. 1997. "The Influence of the Marine Atmospheric Boundary Layer on ERS 1 Synthetic Aperture Radar Imagery of the Gulf Stream." Journal of Geophysical Research C: Oceans 102 (C3): 5799-5814. doi:10.1029/96JC03109.

Bentamy, Abderrahim, and Denis Croize Fillon. 2012. "Gridded Surface Wind Fields from Metop/ASCAT Measurements.” International Journal of Remote Sensing 33 (6): 1729_ 1754. doi:10.1080/01431161.2011.600348.

Boutin, J., Y. Chao, W. E. Asher, T. Delcroix, R. Drucker, K. Drushka, N. Kolodziejczyk, et al. 2016. "Satellite and In Situ Salinity: Understanding Near-Surface Stratification and Subfootprint Variability." Bulletin of the American Meteorological Society 97 (8): 13911407. doi:10.1175/BAMS-D-15-00032.1.

Boutin, J., N. Martin, N. Kolodziejczyk, and G. Reverdin. 2016. "Interannual Anomalies of SMOS Sea Surface Salinity.” Remote Sensing of Environment 180 (July): 128-136. doi:10.1016/j.rse.2016.02.053.

Boutin, J., N. Martin, G. Reverdin, X. Yin, and F. Gaillard. 2013. "Sea Surface Freshening Inferred from SMOS and ARGO Salinity: Impact of Rain.” Ocean Science. doi:10.5194/os9-183-2013.

Chelton, Dudley B., Steven K. Esbensen, Michael G. Schlax, Nicolai Thum, Michael H. Freilich, Frank J. Wentz, Chelle L. Gentemann, Michael J. McPhaden, and Paul S. Schopf. 2001. "Observations of Coupling between Surface Wind Stress and Sea Surface Temperature in the Eastern Tropical Pacific.” Journal of Climate 14 (7): 1479-1498. doi:10.1175/15200442(2001)014<1479:OOCBSW>2.0.CO;2.

Coles, Victoria J., Maureen T. Brooks, Julia Hopkins, Michael R. Stukel, Patricia L. Yager, and Raleigh R. Hood. 2013. "The Pathways and Properties of the Amazon River Plume in the Tropical North Atlantic Ocean.” Journal of Geophysical Research: Oceans 118 (12). John Wiley \& Sons, Ltd: 6894-6913. doi:10.1002/2013JC008981.

Drushka, Kyla, William E. Asher, Brian Ward, and Kieran Walesby. 2016. "Understanding the Formation and Evolution of Rain-Formed Fresh Lenses at the Ocean Surface." Journal of Geophysical Research: Oceans. doi:10.1002/2015JC011527.

Foltz, Gregory R., Semyon A. Grodsky, James A. Carton, and Michael J. McPhaden. 2004. "Seasonal Salt Budget of the Northwestern Tropical Atlantic Ocean along 38 W." Journal of Geophysical Research: Oceans 109 (C3): C03052. doi:10.1029/2003JC002111.

Foltz, Gregory R., and Michael J. McPhaden. 2004. "The 30-70 Day Oscillations in the Tropical Atlantic." Geophysical Research Letters 31 (15). John Wiley \& Sons, Ltd: L15205. doi:10.1029/2004GL020023. 
482

483

484

485

486

487

488

489

490

491

492

493

494

495

496

Grodsky, S. A., and J. A. Carton. 2001. "Coupled Land/Atmosphere Interactions in the West African Monsoon.” Geophysical Research Letters 28 (8): 1503-1506. doi:10.1029/2000GL012601.

Grodsky, Semyon A., James A. Carton, and Frank O. Bryan. 2014. "A Curious Local Surface Salinity Maximum in the Northwestern Tropical Atlantic." Journal of Geophysical Research: Oceans 119 (1): 484-495. doi:10.1002/2013JC009450.

Grodsky, Semyon A., James A. Carton, and Charles R. McClain. 2008. "Variability of Upwelling and Chlorophyll in the Equatorial Atlantic." Geophysical Research Letters 35 (3): L03610. doi:10.1029/2007GL032466.

Grodsky, Semyon A., James A. Carton, Christine Provost, Jacques Servain, Joao A. Lorenzzetti, and Michael J. McPhaden. 2005. "Tropical Instability Waves at $0^{\circ} \mathrm{N}, 23^{\circ} \mathrm{W}$ in the Atlantic: A Case Study Using Pilot Research Moored Array in the Tropical Atlantic (PIRATA) Mooring Data." Journal of Geophysical Research 110 (C8). John Wiley \& Sons, Ltd: C08010. doi:10.1029/2005JC002941.

$\mathrm{Gu}$, Guojun. 2009. "Intraseasonal Variability in the Equatorial Atlantic-West Africa during March-June." Climate Dynamics. doi:10.1007/s00382-008-0428-0.

Guan, Bin, Tong Lee, Daria J. Halkides, and Duane E. Waliser. 2014. "Aquarius Surface Salinity and the Madden-Julian Oscillation: The Role of Salinity in Surface Layer Density and Potential Energy." Geophysical Research Letters 41 (8): 2858-2869. doi:10.1002/2014GL059704.

Hasson, Audrey, John Thomas Farrar, Jacqueline Boutin, Frederick Bingham, and Tong Lee. 2019. "Intraseasonal Variability of Surface Salinity in the Eastern Tropical Pacific Associated With Mesoscale Eddies." Journal of Geophysical Research: Oceans 124 (4): 2861-2875. doi:10.1029/2018JC014175.

Huffman, George J., David T. Bolvin, Eric J. Nelkin, David B. Wolff, Robert F. Adler, Guojun Gu, Yang Hong, et al. 2007. "The TRMM Multisatellite Precipitation Analysis (TMPA): Quasi-Global, Multiyear, Combined-Sensor Precipitation Estimates at Fine Scales.” Journal of Hydrometeorology 8 (1): 38-55. doi:10.1175/JHM560.1.

Kiladis, George N., Matthew C. Wheeler, Patrick T. Haertel, Katherine H. Straub, and Paul E. Roundy. 2009. "Convectively Coupled Equatorial Waves." Reviews of Geophysics 47 (2). John Wiley \& Sons, Ltd: RG2003. doi:10.1029/2008RG000266.

Krishnamurti, T. N., and H. N. Bhalme. 1976. "Oscillations of a Monsoon System. Part I. Observational Aspects." Journal of the Atmospheric Sciences 33 (10): 1937-1954. doi:10.1175/1520-0469(1976)033<1937:OOAMSP>2.0.CO;2.

Lee, Tong. 2016. "Consistency of Aquarius Sea Surface Salinity with Argo Products on Various Spatial and Temporal Scales." Geophysical Research Letters 43 (8): 3857-3864. doi:10.1002/2016GL068822.

Lee, Tong, Gary Lagerloef, Michelle M. Gierach, Hsun-Ying Kao, Simon Yueh, and Kathleen Dohan. 2012. "Aquarius Reveals Salinity Structure of Tropical Instability Waves." Geophysical Research Letters 39 (12): n/a-n/a. doi:10.1029/2012GL052232. 
Lee, Tong, Gary Lagerloef, Hsun-Ying Kao, Michael J. McPhaden, Joshua Willis, and Michelle M. Gierach. 2014. "The Influence of Salinity on Tropical Atlantic Instability Waves." Journal of Geophysical Research: Oceans 119 (12): 8375-8394. doi:10.1002/2014JC010100.

Liu, Hailong, Semyon A. Grodsky, and James A. Carton. 2009. "Observed Subseasonal Variability of Oceanic Barrier and Compensated Layers." Journal of Climate 22 (22): 6104-6119. doi:10.1175/2009JCLI2974.1.

Lyman, John M., Gregory C. Johnson, and William S. Kessler. 2007. "Distinct 17- and 33-Day Tropical Instability Waves in Subsurface Observations*." Journal of Physical Oceanography 37 (4): 855-872. doi:10.1175/JPO3023.1.

Maloney, Eric D., and Jeffrey Shaman. 2008. "Intraseasonal Variability of the West African Monsoon and Atlantic ITCZ." Journal of Climate 21 (12): 2898-2918. doi:10.1175/2007JCLI1999.1.

McClain, Charles R., James R. Christian, Sergio R. Signorini, Marlon R. Lewis, Ichio Asanuma, Daniela Turk, and Cecile Dupouy-Douchement. 2002. "Satellite Ocean-Color Observations of the Tropical Pacific Ocean." Deep Sea Research Part II: Topical Studies in Oceanography 49 (13-14): 2533-2560. doi:10.1016/S0967-0645(02)00047-4.

Meissner, Thomas, Frank J. Wentz, Joel Scott, and Jorge Vazquez-Cuervo. 2016. "Sensitivity of Ocean Surface Salinity Measurements From Spaceborne L-Band Radiometers to Ancillary Sea Surface Temperature." IEEE Transactions on Geoscience and Remote Sensing 54 (12): 7105-7111. doi:10.1109/TGRS.2016.2596100.

Meissner, Thomas, Frank J. Wentz, and David M. Le Vine. 2018. "The Salinity Retrieval Algorithms for the NASA Aquarius Version 5 and SMAP Version 3 Releases." Remote Sensing 10 (7). Multidisciplinary Digital Publishing Institute: 1121. doi:10.3390/rs10071121.

Melnichenko, Oleg, Angel Amores, Nikolai Maximenko, Peter Hacker, and James Potemra. 2017. "Signature of Mesoscale Eddies in Satellite Sea Surface Salinity Data." Journal of Geophysical Research: Oceans. doi:10.1002/2016JC012420.

Polito, Paulo S., John P. Ryan, W. Timothy Liu, and Francisco P. Chavez. 2001. "Oceanic and Atmospheric Anomalies of Tropical Instability Waves." Geophysical Research Letters 28 (11): 2233-2236. doi:10.1029/2000GL012400.

Sena Martins, Meike, Nuno Serra, and Detlef Stammer. 2015. "Spatial and Temporal Scales of Sea Surface Salinity Variability in the Atlantic Ocean." Journal of Geophysical Research: Oceans 120 (6): 4306-4323. doi:10.1002/2014JC010649.

Shinoda, Toshiaki, Tommy Jensen, Maria Flatau, Sue Chen, Weiqing Han, and Chunzai Wang. 2013. "Large-Scale Oceanic Variability Associated with the Madden-Julian Oscillation during the CINDY/DYNAMO Field Campaign from Satellite Observations." Remote Sensing 5 (5): 2072-2092. doi:10.3390/rs5052072.

Supply, A., J. Boutin, J.-L. Vergely, N. Martin, A. Hasson, G. Reverdin, C. Mallet, and N. Viltard. 2018. "Precipitation Estimates from SMOS Sea-Surface Salinity." Quarterly 
Journal of the Royal Meteorological Society 144 (November): 103-119. doi:10.1002/qj.3110.

Tomaziello, Ana Carolina Nóbile, Leila M. V. Carvalho, and Adilson W. Gandu. 2016. "Intraseasonal Variability of the Atlantic Intertropical Convergence Zone during Austral Summer and Winter." Climate Dynamics 47 (5-6): 1717-1733. doi:10.1007/s00382-0152929-y.

Tzortzi, Eleni, Meric Srokosz, Christine Gommenginger, and Simon A. Josey. 2016. "Spatial and Temporal Scales of Variability in Tropical Atlantic Sea Surface Salinity from the SMOS and Aquarius Satellite Missions.” Remote Sensing of Environment 180 (July): 418-430. doi:10.1016/j.rse.2016.02.008.

Vizy, Edward K., and Kerry H. Cook. 2010. "Influence of the Amazon/Orinoco Plume on the Summertime Atlantic Climate.” Journal of Geophysical Research 115 (D21): D21112. doi:10.1029/2010JD014049.

Weisberg, Robert H., and Thomas J. Weingartner. 1988. "Instability Waves in the Equatorial Atlantic Ocean." Journal of Physical Oceanography 18 (11): 1641-1657. doi:10.1175/1520-0485(1988)018<1641:IWITEA>2.0.CO;2.

Yin, Xiaobin, Jacqueline Boutin, Gilles Reverdin, Tong Lee, Sabine Arnault, and Nicolas Martin. 2014. "SMOSSea Surface Salinity Signals of Tropical Instability Waves." Journal of Geophysical Research: Oceans 119 (11): 7811-7826. doi:10.1002/2014JC009960.

Yu, Lisan. 2011. "A Global Relationship between the Ocean Water Cycle and Near-Surface Salinity.” Journal of Geophysical Research 116 (C10): C10025. doi:10.1029/2010JC006937.

Yu, Lisan. 2015. "Sea-Surface Salinity Fronts and Associated Salinity-Minimum Zones in the Tropical Ocean." Journal of Geophysical Research: Oceans 120 (6): 4205-4225. doi:10.1002/2015JC010790. 
Figures
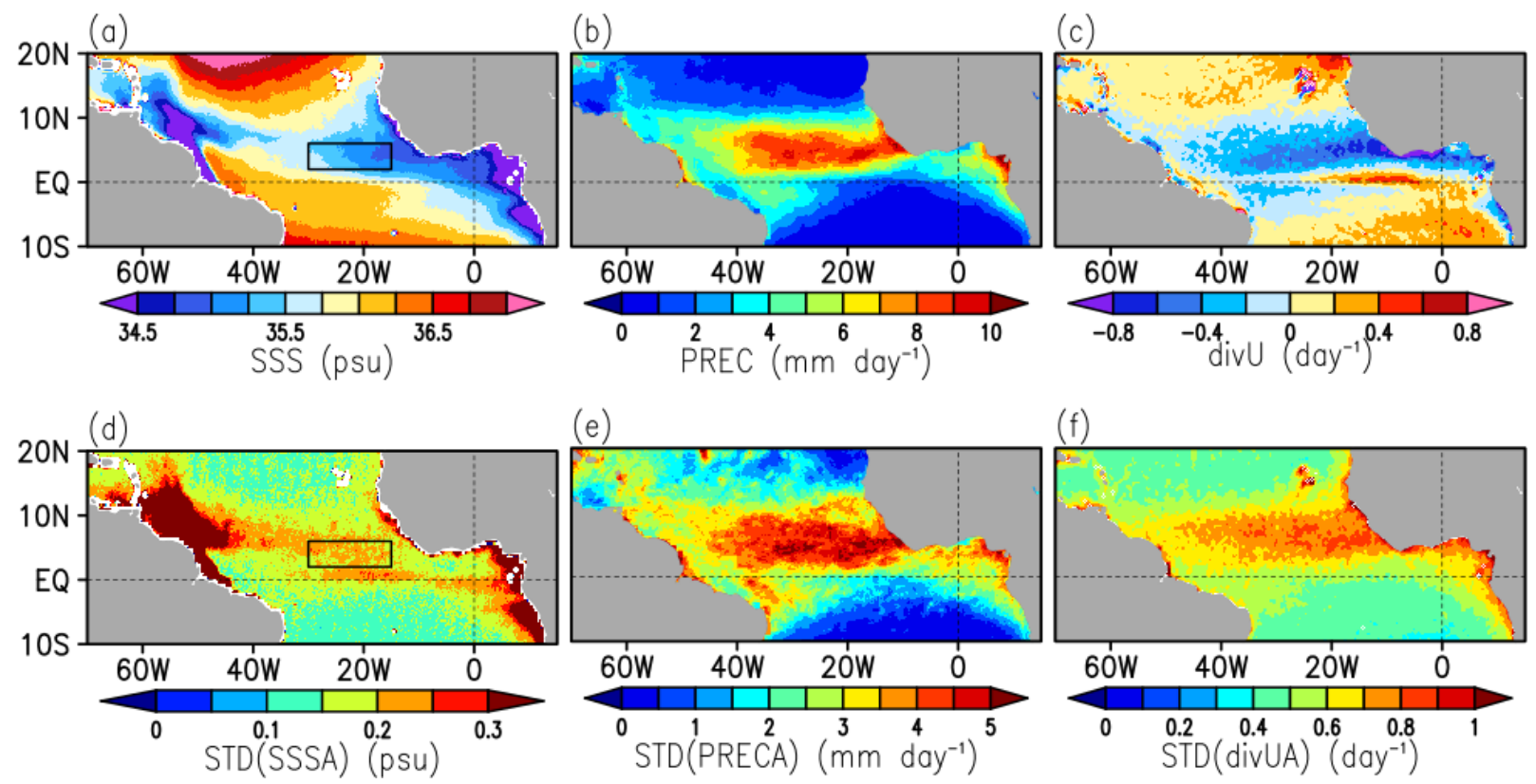

Figure 1. Time mean (a) sea surface salinity (SSS), (b) precipitation (PREC), and (c) nearsurface wind divergence (divU). Standard deviation of intramonth (d) SSS anomaly, (e) PREC anomaly, and (f) divU anomaly. Intramonth variation is defined as a deviation from the monthly running mean. Central tropical Atlantic box is shown in (a, d). 


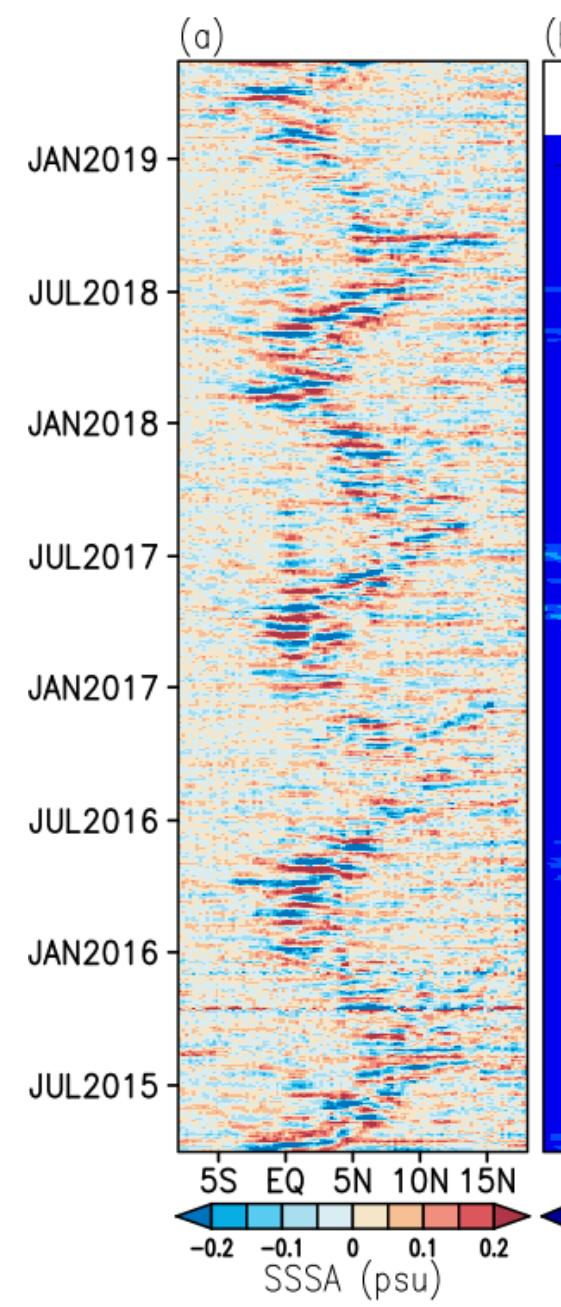

(b)

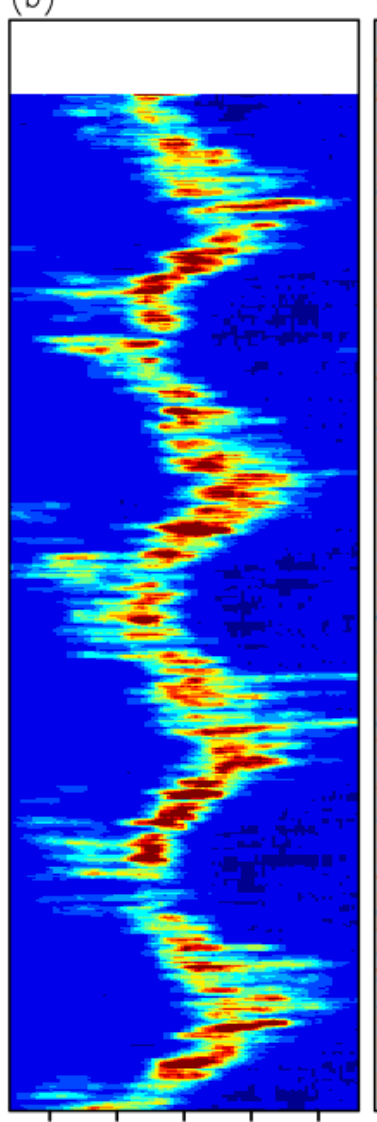

$5 S$ EQ $5 \mathrm{~N} \quad 10 \mathrm{~N} 15 \mathrm{~N}$ (c)

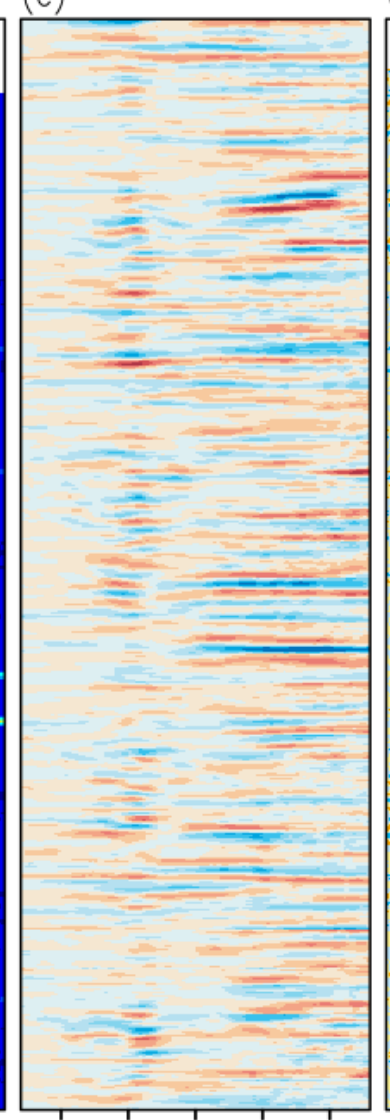

$5 S^{\prime} E^{\prime} \quad N^{\prime} 10 \mathrm{~N} 15 \mathrm{~N}$ (d)

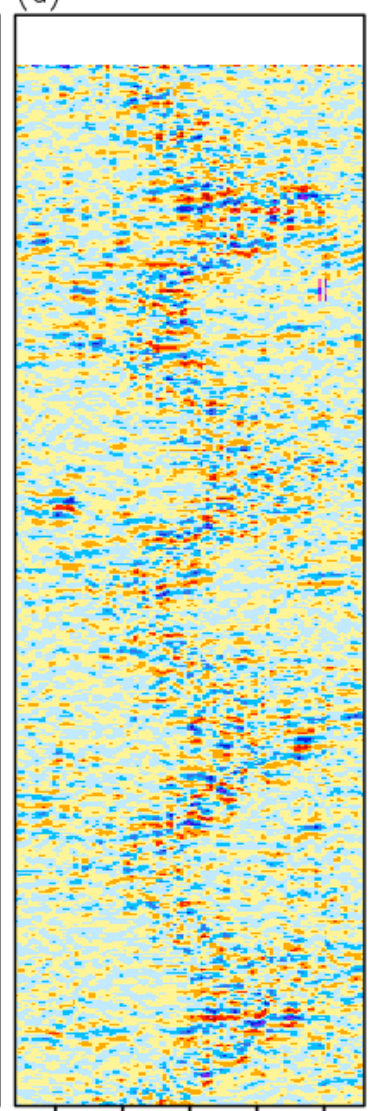

$5 S$ EQ $5 N 10 N 15 N$

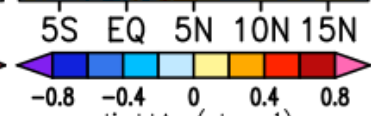

Figure 2. Time-latitude diagram of zonally averaged (a) intramonth sea surface salinity anomaly (SSSA), (b) total precipitation (PREC), intramonth sea surface temperature anomaly (SSTA), and intramonth surface wind divergence anomaly (divUA). Zonal averaging is done over longitude extent of the box in Fig. $1 \mathrm{a}\left(30^{\circ} \mathrm{W}-15^{\circ} \mathrm{W}\right)$. 

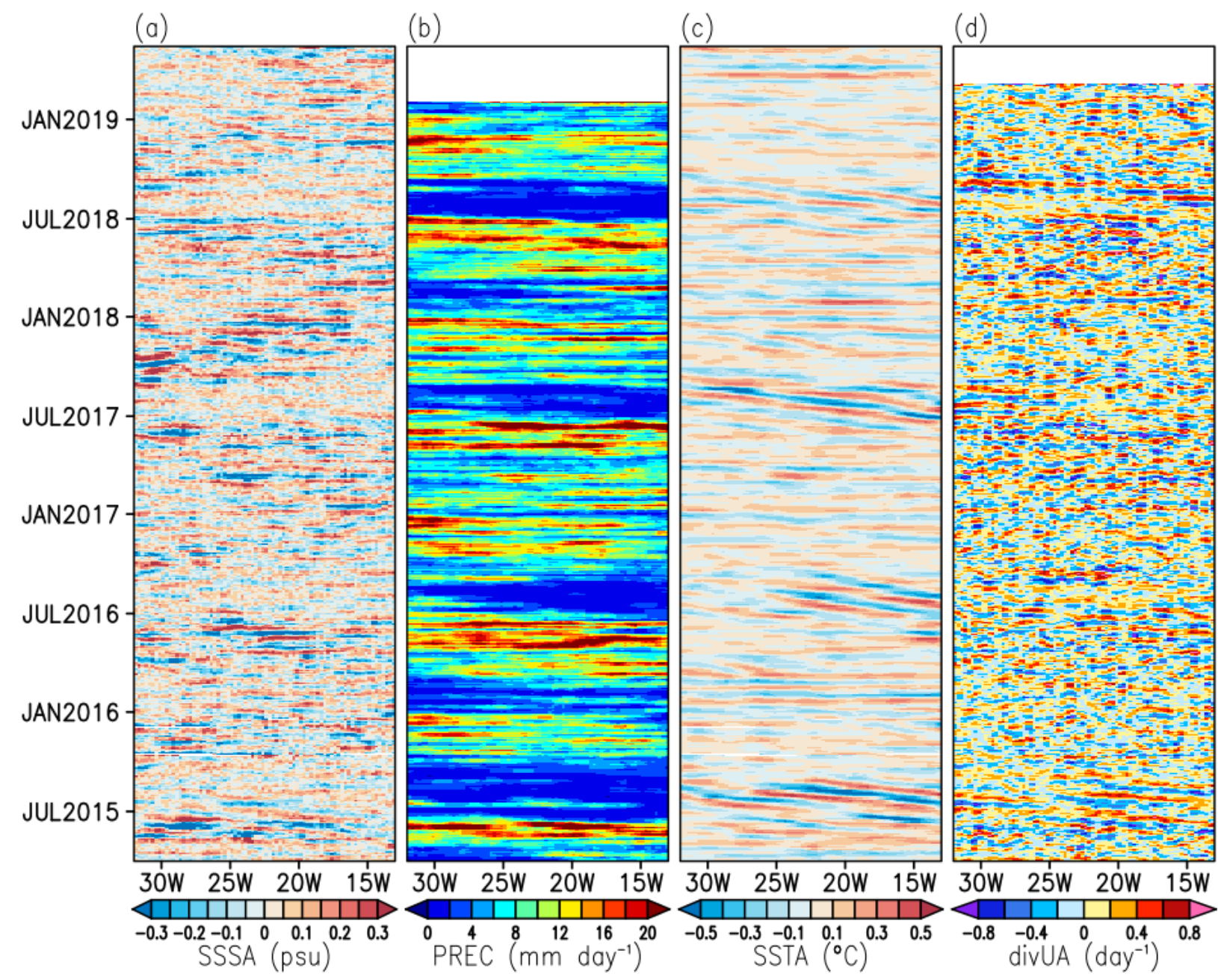

Figure 3. Time-longitude diagram of meridionally averaged (a) intramonth sea surface salinity anomaly (SSSA), (b) total precipitation (PREC), intramonth sea surface temperature anomaly (SSTA), and (d) intramonth surface wind divergence anomaly (divUA). Meridional averaging is done over latitude extent of the box in Fig. $1 \mathrm{a}\left(2^{\circ} \mathrm{N}-6^{\circ} \mathrm{N}\right)$. 


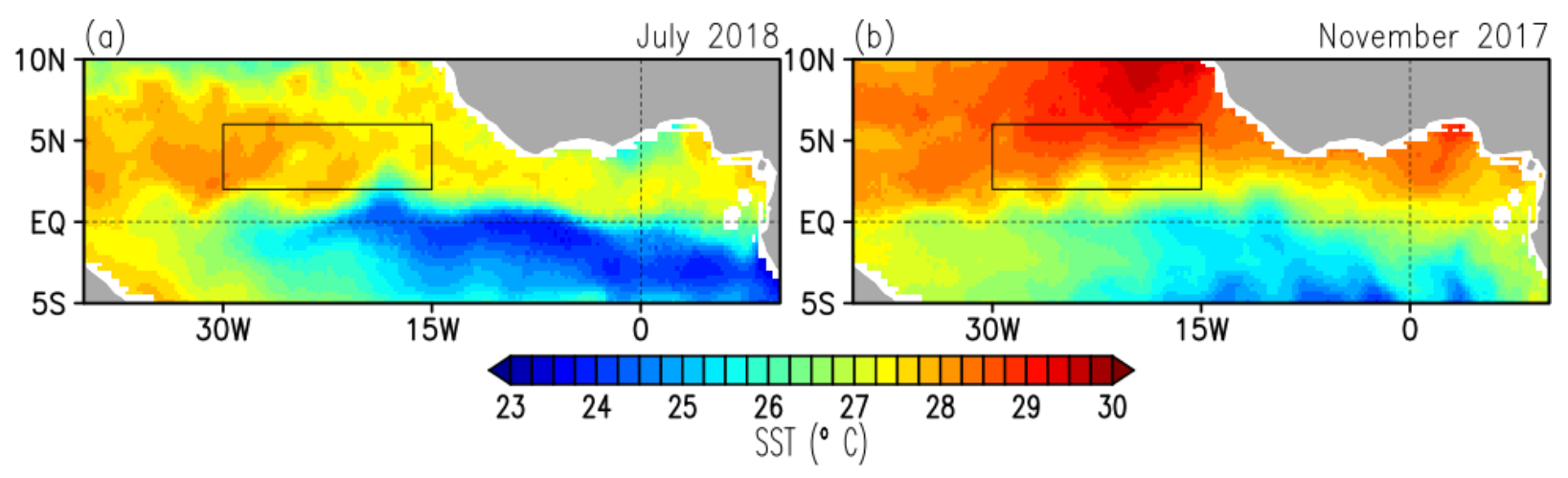

Figure 4. Sample daily SST maps illustrating TIW length scale with respect to the averaging box size in (a) summer (b) fall-winter. 

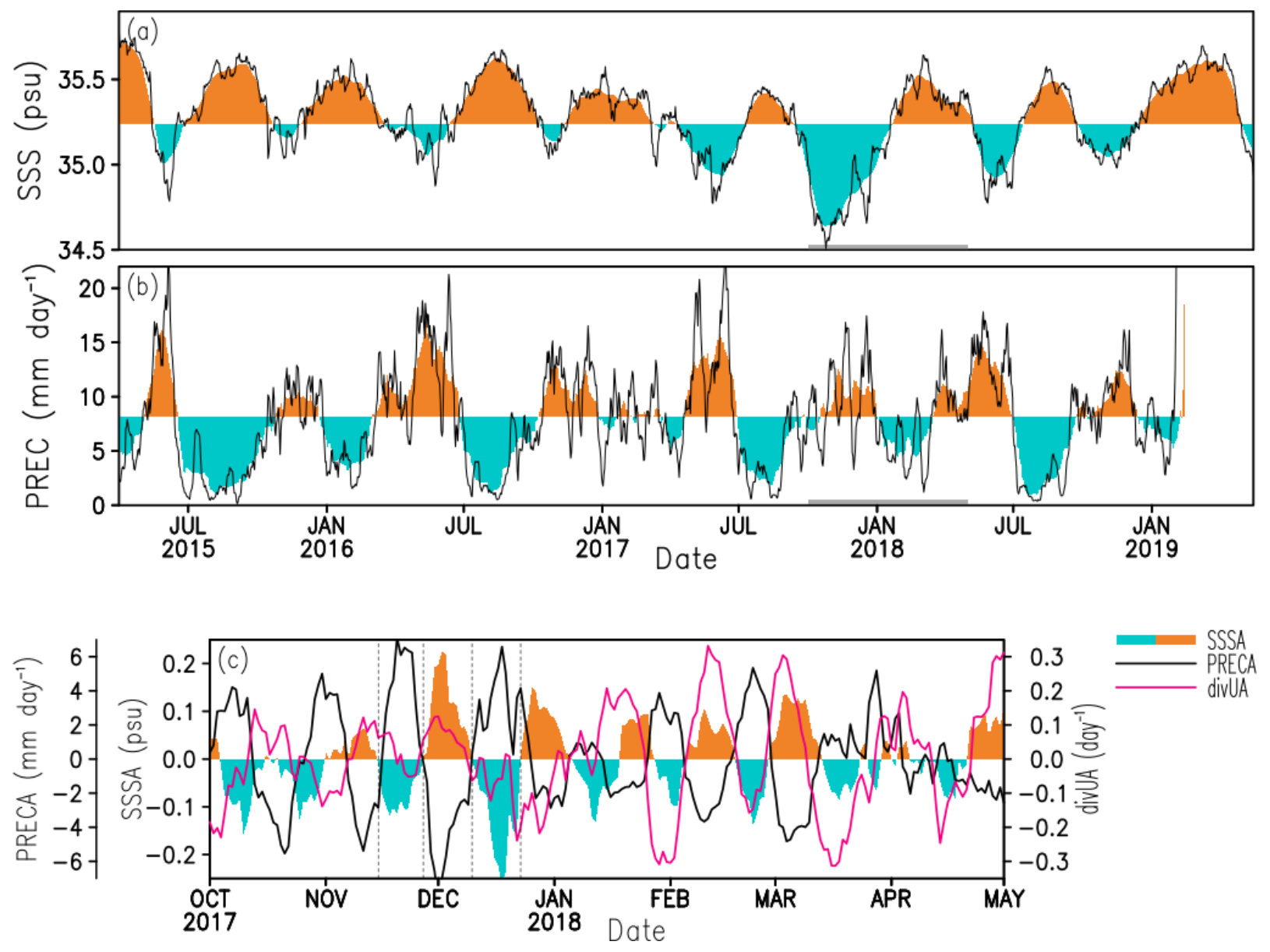

Figure 5. Box averaged time series of (shaded) monthly running mean and (black line) 8-day mean (a) sea surface salinity (SSS), (b) precipitation (PREC), (c) intramonth anomalies of sea surface salinity (SSSA), precipitation (PRECA), and wind divergence (divUA) zoomed over the time period marked by gray rectangles in $(a, b)$. See Fig. 1a for the box location. Vertical dashed lines in (c) delineate a sequence of SSS anomalies detailed in Figs. 9, 10. 

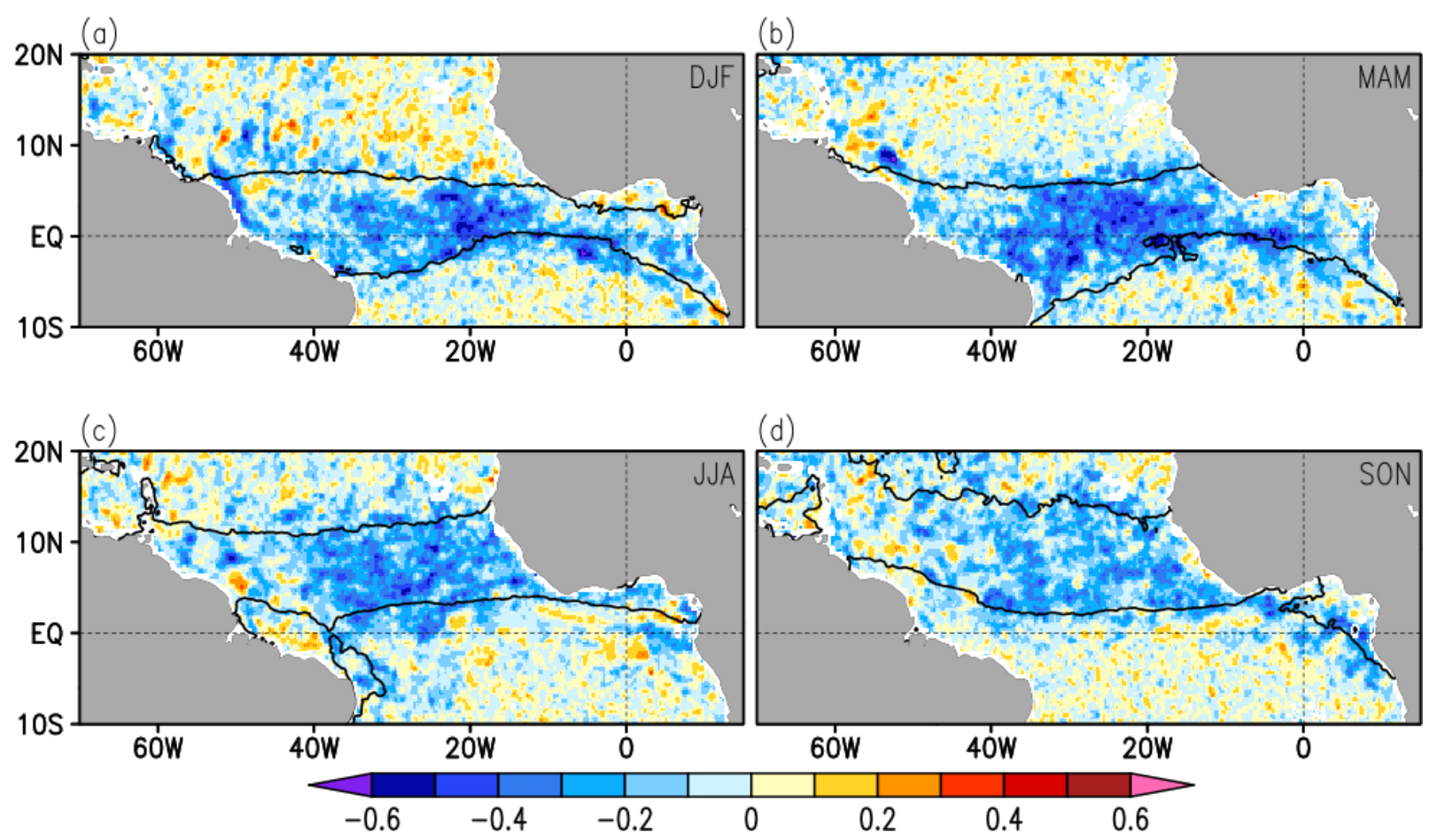

Figure 6. Temporal correlation of intramonth variations of sea surface salinity and precipitation for each season. Black contours show $3 \mathrm{~mm}_{\text {day }}{ }^{-1}$ precipitation to illustrate the ITCZ position. Correlation magnitude $>0.14$ is statistically significant at the $99 \%$ level. 

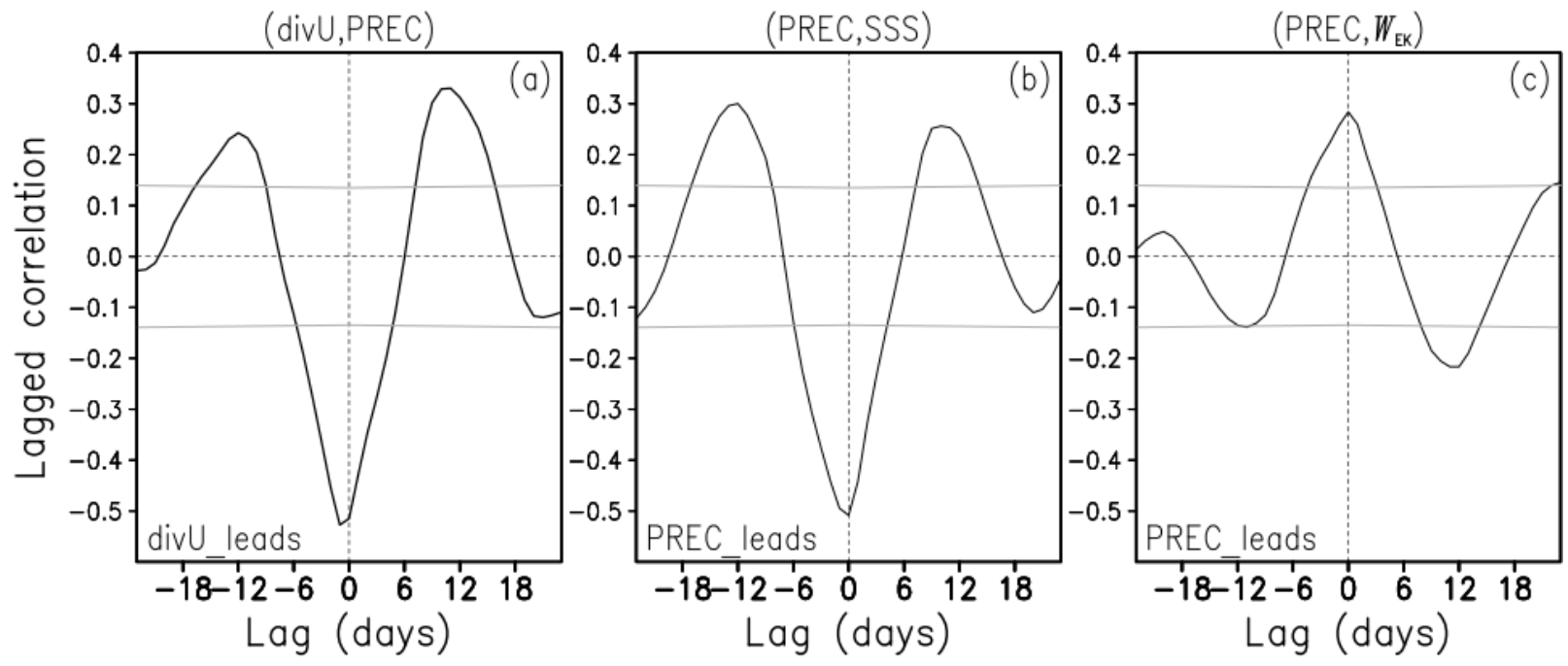

Figure 7. Lagged correlation of box-averaged intramonth anomalies of (a) near surface wind divergence and precipitation (divU, PREC), (b) precipitation and sea surface salinity (PREC, SSS), and (c) precipitation and vertical Ekman velocity (PREC, $W_{\mathrm{EK}}$ ). $W_{\mathrm{EK}}>0$ is upward. See Fig. 1a for the box location. All correlations are based on 8-day running means. The $99 \%$ 600 confidence intervals of zero correlation are shown by solid gray. 
603
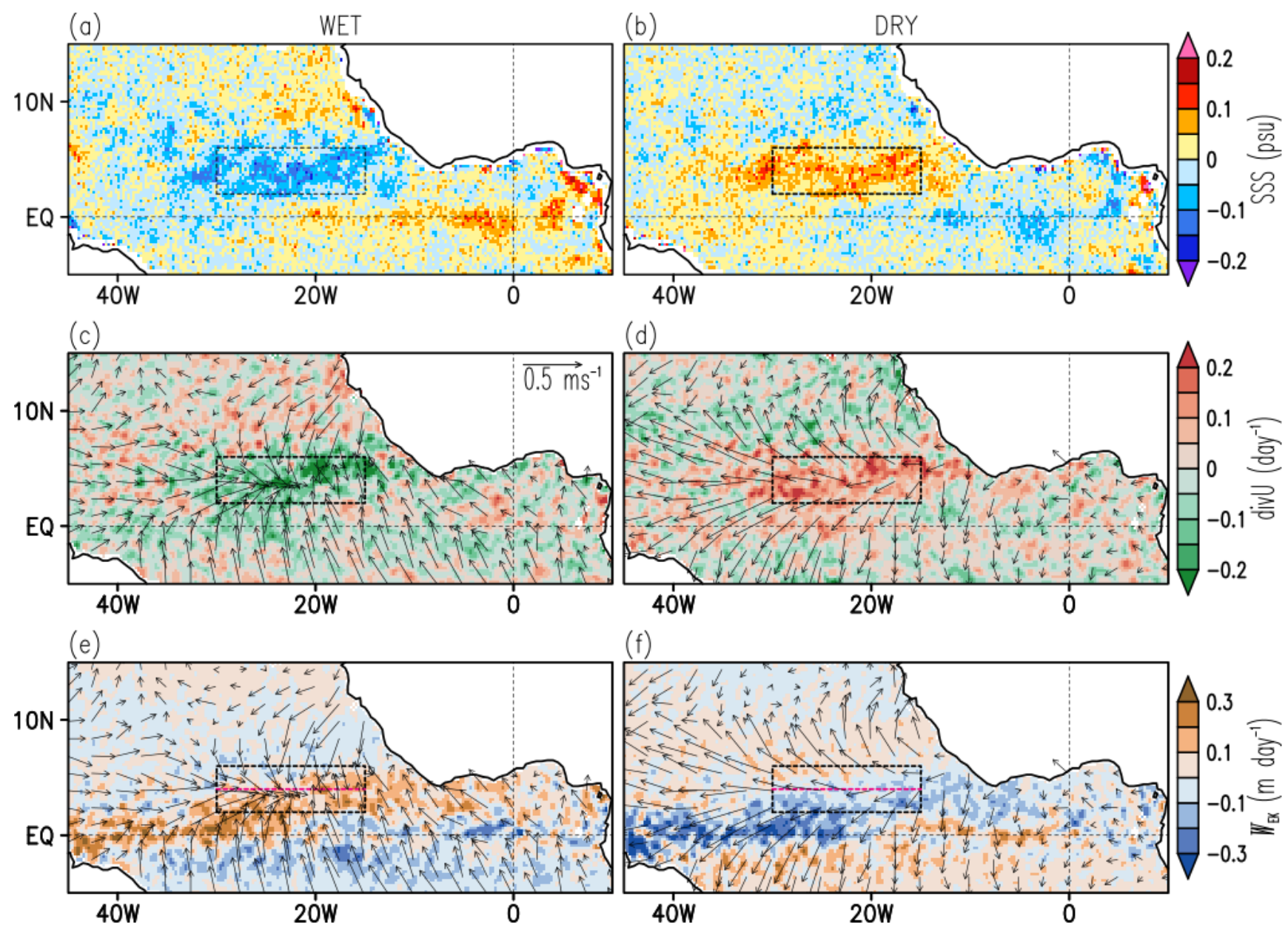

Figure 8. Composite maps of anomalies corresponding to (a, c, e) wet and (b, d, f) dry events in the central Atlantic box (black rectangle) for (a, b) SSS, (c, d) divU, and (e, f) Ekman pumping velocity $\left(W_{\mathrm{EK}}\right)$. Events are defined as periods when the magnitude of box averaged intramonth rainfall exceeds its standard deviation. Arrows show corresponding intramonth wind anomaly composites. Central 604 latitude of the box is shown by magenta in (e, $\mathrm{f})$. 
606

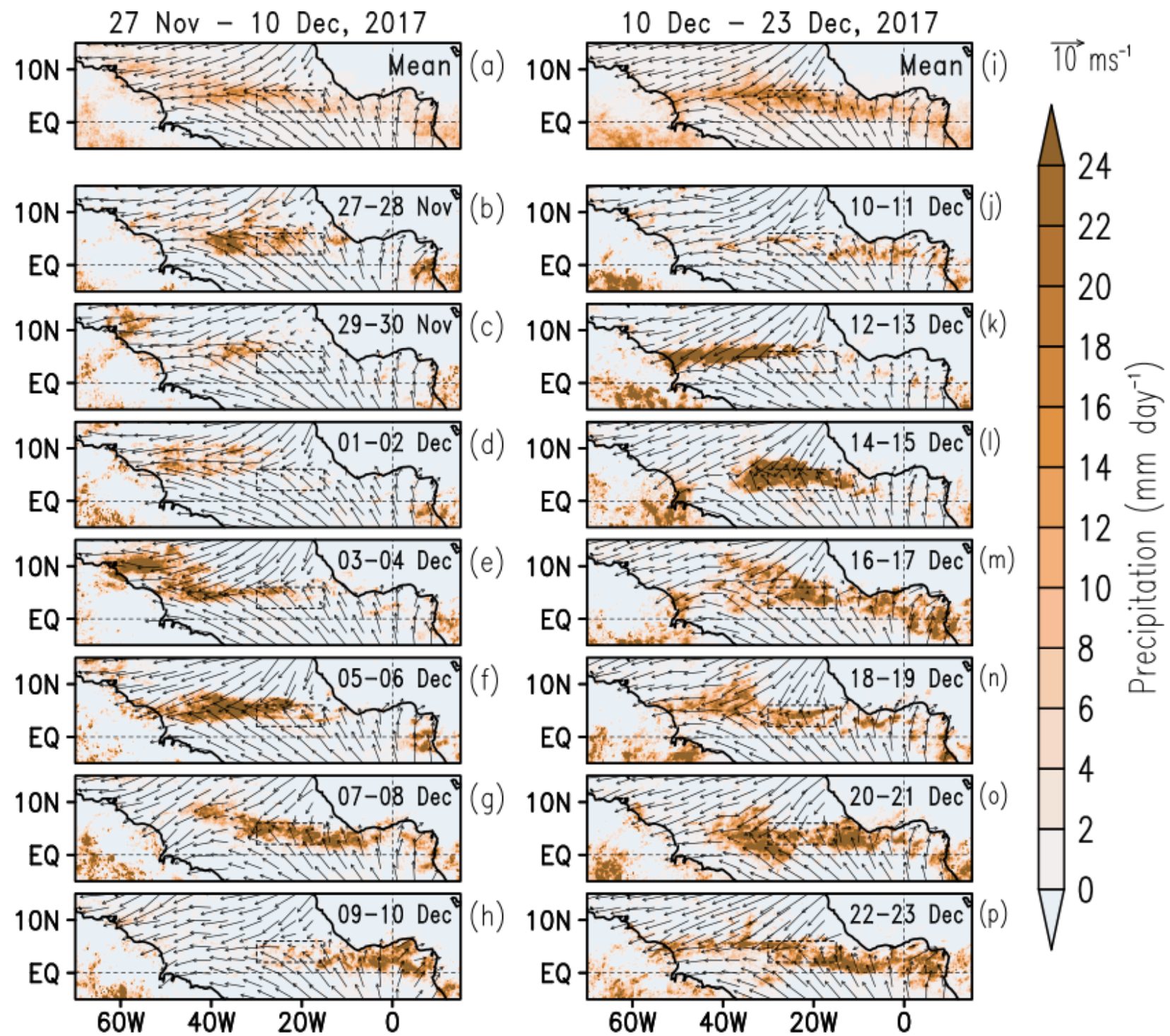

Figure 9. Time evolution of 2-day mean (shaded) precipitation and (arrows) winds during (b-h) 27 November-10 December dry event and (j-p) 10 December-23 December wet event (see Fig. 5c), (a) and (i) show event-mean fields. Central tropical Atlantic box (the same as in Fig. 1a) is also shown. 607

608 
609

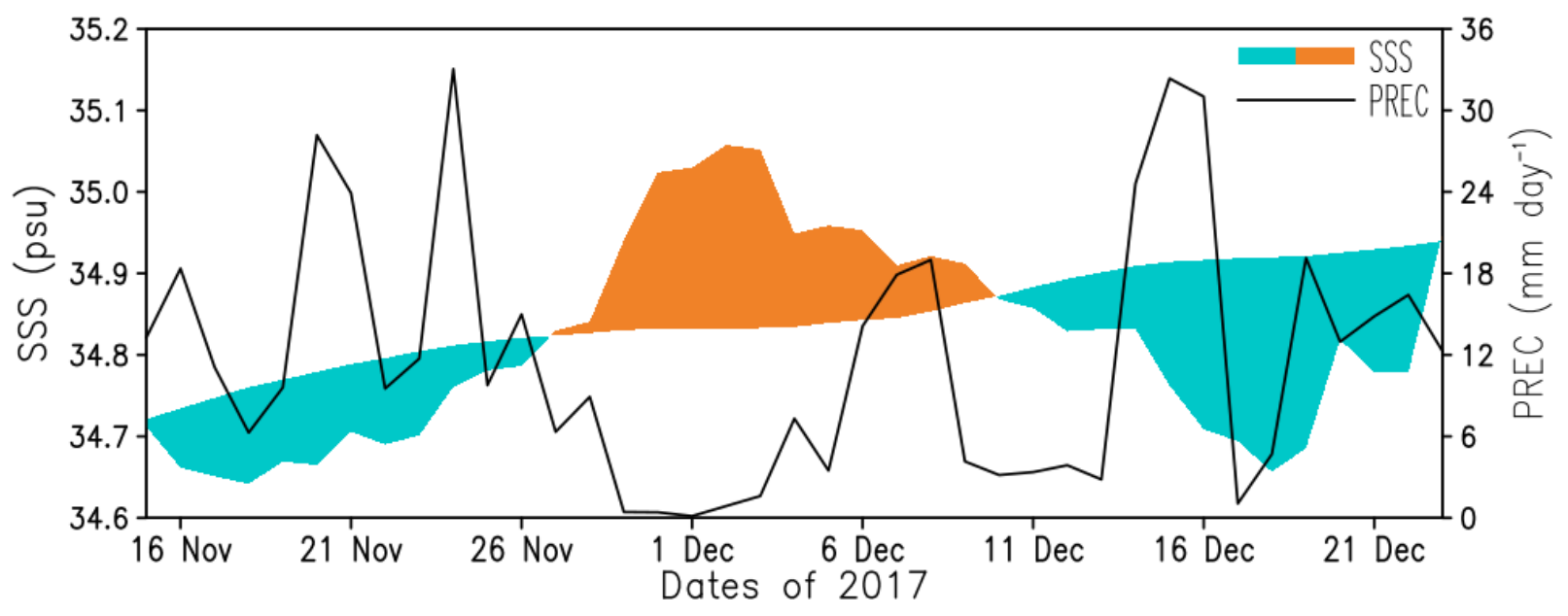

Figure 10. Time series of box averaged (shaded) sea surface salinity (SSS) and precipitation (PREC) during the 3 events delineated in Fig. 5c. Baseline for SSS is its running monthly mean. Daily mean PREC is shown in distinction from Fig. 5c, where 8-day mean PREC is shown. See Fig. 1a for the box location. 


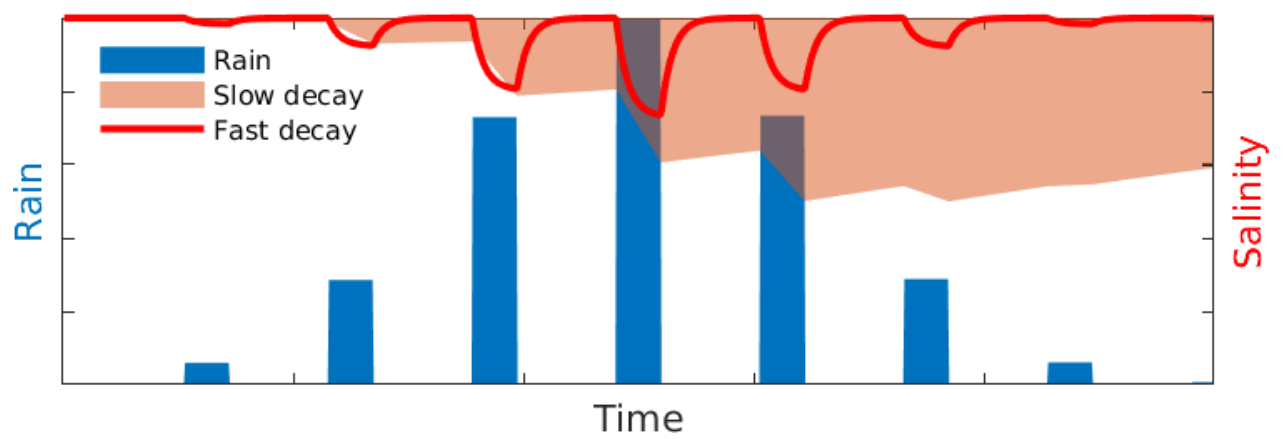

Figure 11. Schematic diagram of salinity response to intermittent rain events (blue) for slow (shaded) and fast (red line) fresh salinity anomaly decay time. 
612
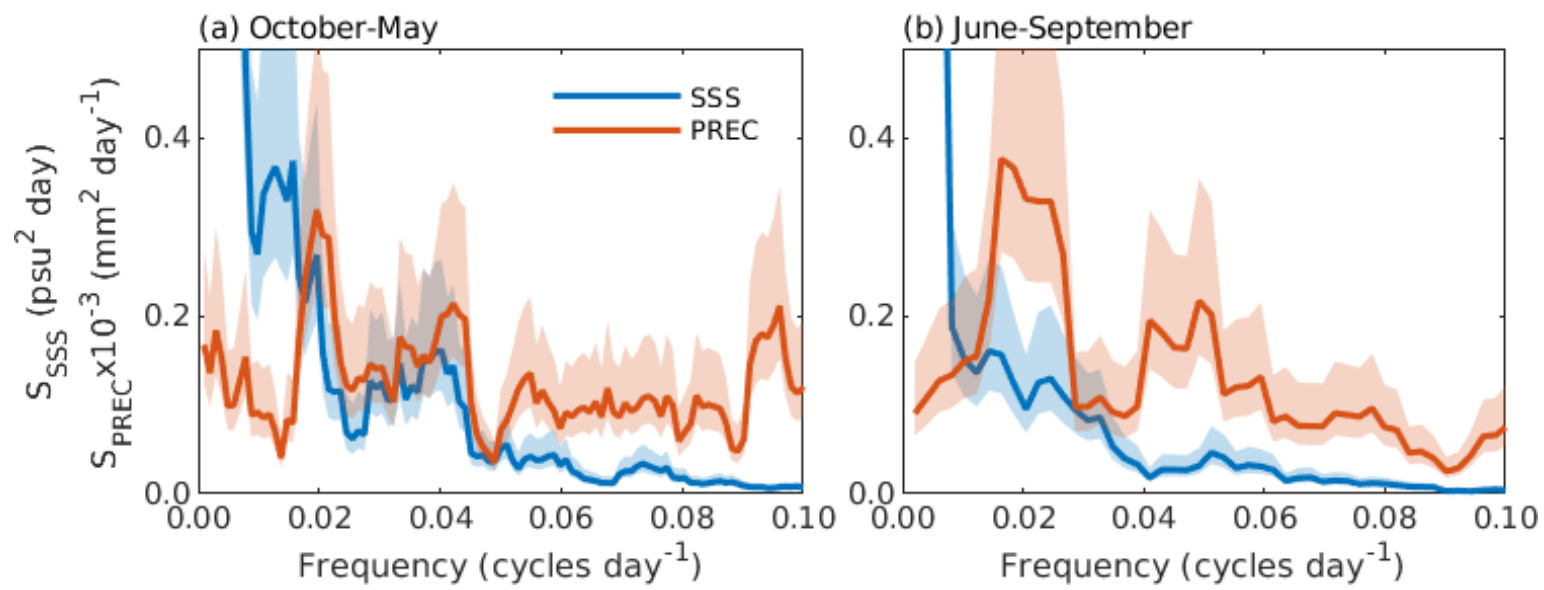

Figure 12. Frequency spectra of anomalous SSS $\left(S_{\mathrm{SSS}}\right)$ and precipitation $\left(S_{\mathrm{PREC}}\right)$ spatially averaged over the fixed central tropical Atlantic box (see Fig.1a for the box location) when the ITCZ seasonally shifts south (a) and north (b). Shading represents the $67 \%$ spectral confidence intervals. Anomalies are calculated versus the seasonal cycle. Intramonth filtering is not applied. Spectra are shown in linear scale and normalized by the corresponding signal variance. 